\title{
Status Inequality, Moral Disengagement and Violence
}

\author{
Armin Falk
}

Working Paper

2017-057

$07 / 2017$ 


\title{
Status Inequality, Moral Disengagement and Violence
}

\author{
Armin Falk*
}

July 17, 2017

\begin{abstract}
This paper studies the causal effect of status differences on moral disengagement and violence. To measure violent behavior, in the experiment, a subject can inflict a painful electric shock on another subject in return for money. We exogenously vary relative status in the realm of sexual attractiveness. In three between-subject conditions, the assigned other subject is either of higher, lower or equal status. The incidence of electric shocks is substantially higher among subjects matched with higher- and lower-status others, relative to subjects matched with equal-status others. This causal evidence on the role of status inequality on violence suggests an important societal cost of economic and social inequalities.
\end{abstract}

JEL classification: A13, C91, D03, Z13

Keywords: Morality, Violence, Status, Inequality, Laboratory Experiments

*Institute on Behavior and Inequality (briq) and University of Bonn, Department of Economics, Adenauerallee 24-42, 53113 Bonn, Germany; armin.falk@briq-institute.org.

I would like to thank Thomas Graeber for excellent research assistance and Johannes Abeler, David Huffman, Simon Jaeger, Frederik Schwerter and Jean Tirole for helpful comments. 


\section{Introduction}

"It is fatal to look hungry. It makes people want to kick you."

- George Orwell, Down and Out in Paris and London (1933)

This paper establishes a causal effect of status inequality on moral disengagement and the incidence of violence. Identifying status differences as a potential source of moral disengagement is arguably important for several reasons. Not only do status inequalities pervade human societies; they have increased in recent decades as a consequence of growing economic and social inequalities. ${ }^{1}$ Moral disengagement is particularly costly when engendering violent behavior, as suggested by a large body of research quantifying the welfare cost of violence (e.g., Anderson, 1999; Soares, 2006; Thaler, 1978). Status-driven moral disengagement does not only manifest itself in violence, however, but also affects who is viewed as deserving and who is not. This has a bearing, e.g., on societal preferences for redistribution, which, in turn, may explain differences in the generosity of welfare systems (Alesina et al., 2001) and are central to the design of optimal policies and tax schedules (Saez and Stantcheva, 2016). The importance of status inequality as a central mechanism for socially undesirable outcomes is reinforced by the fact that perceptions of status differences can be (and actually are) manipulated politically, e.g., in campaigning against ethnic or religious groups. ${ }^{2}$ Our findings therefore illustrate an important societal cost of status inequality in threatening social and political cohesion.

Previous non-experimental findings suggesting a link between social status and the incidence of violence encompass the envious hate directed at Tutsis in Rwanda or Jews in the reign of the Nazis (Glick, 2002), or the scornful neglect of the homeless, poor and people of lower castes (Fiske, 2010). Likewise, several studies provide descriptive evidence for a positive relation between societal inequality and violence (Blau and Blau, 1982; Daly et al., 2001; Hsieh and Pugh, 1993; Fajnzylber et al., 2002; Kelly, 2000; Wilkinson, 2004). ${ }^{3}$ In this respect,

\footnotetext{
${ }^{1}$ See, e.g., Card et al. (2013) Dustmann et al. (2009), Song et al. (2015) for evidence on increasing inequalities in recent decades, and, e.g., Bowles and Park (2005), Roberts (2011), Wilkinson and Pickett (2009) for a link between inequality and status differences, e.g., due to an increased concern with social hierarchy in unequal societies.

${ }^{2}$ A historical example is Nazi ideology, using "dehumanizing language" to degrade Jews and other victims to a "lesser" race and a "subhuman" level (Zimbardo, 2007; Bandura, 1999; Glover, 2012; Petrinovich and O'Neill, 1996). Glaeser (2005) formalizes the notion that politicians seek to expand political power by sowing hatred against a minority through means of creating and spreading stories. Tirole et al. (2017) show how narratives can function as an excuse to engage in immoral behavior, and study how these narratives spread out.

${ }^{3} \mathrm{~A}$ number of risk factors for violence have been identified, including increased levels of unemployment, poverty, decreased levels of economic opportunities or poor housing conditions, see, e.g., Lipsey and Derzon
} 
exposure to violence appears to be particularly pronounced in households with low socioeconomic background. ${ }^{4}$ Using historical or non-experimental data, however, renders a causal interpretation of the effect of status on violence notoriously difficult. Moreover, with field data it is virtually impossible to disentangle differences in economic conditions from status effects, and it often remains unclear whether observed violence is targeted at others of similar, higher or lower status, respectively. In this paper, we therefore report controlled laboratory evidence showing that among otherwise identical individuals, status differences indeed increase the incidence of violent behavior towards others of higher or lower status, relative to equal-status others.

An experimental research design to study the causal effect of status inequality on moral disengagement and violence faces several challenges. First, we need to create status differences in a self-relevant domain, i.e., the induced differences must be meaningful to participants in order to qualify as status-relevant. Second, status differences need to be randomly assigned among otherwise identical individuals to rule out potential confounds, e.g., economic conditions, and to allow for a causal interpretation of our findings. Third, from the perspective of an individual, status differences can logically take three forms as either low status (comparing upwards, possibly evoking feelings of envy), high status (comparing downwards, potentially evoking scorn) and similar status (comparing to similar others). To comprehensively study status effects and the potential asymmetry between high- and low-status comparisons, it is therefore essential to assign low, high and equal status. Finally, we need to observe a valid and well-defined outcome measure of violent or immoral behavior.

To meet these requirements, in the experiment status differences are introduced in the realm of sexual attractiveness, a domain that is of obvious self-relevance. ${ }^{5}$ Subjects are randomly assigned to either high, low or equal status based on ratings of their sexual attractiveness (1998), Resnick et al. (2004), World Health Organization (2002). Using data recorded by the German Federal Criminal Police Office, Falk et al. (2011) report a significant positive relation between unemployment and right-wing criminal activities.

${ }^{4}$ Browne et al. (1999) report that women who resided in households with low earning were morel likely to experience violence than women in wealthier households. Moreover, Bassuk et al. (1996) found that homeless mothers were significantly more often exposed to physical and sexual assault than low-income housed mothers. Buka et al. (2001) found that in comparison to middle and high income neighborhoods, youths from low-income neighborhoods witnessed significantly more severe violence (such as murder).

${ }^{5}$ Differential success in mating is central to the evolutionary process in sexually reproducing organisms (Maner et al., 2005), attractiveness is associated with social status (Kalick, 1988), and differences in attractiveness have repeatedly been identified as a potential source of envy (Smith et al., 1999). 
relative to another (passive) participant. The ratings are provided by a group of three "attractive young women/men" based on pictures which the participants had sent to us prior to the experimental sessions. To measure moral disengagement and violence, subjects make a binary choice between two options, labeled option A and option B, respectively: Choosing option B implies that the subject is paid 7 euros, and the other participant receives a painful electric shock. Option A implies that the participant does not receive additional money, and no pain is inflicted.

Our results provide striking support for the effect of status inequality on moral disengagement and the willingness to act violently. We observe substantially higher shocking rates when subjects are matched with higher- and lower-status others, in comparison to subjects matched with equal-status others. While in the equal status condition the fraction of subjects inflicting pain is 29.6 percent, it increases to more than 70 percent when facing another subject of either higher or lower status, respectively. Interestingly, the effect size is equally strong for highand low-status individuals, suggesting that relative status does not only matter in terms of envy (towards high status others), but also in terms of scornful neglect (towards low-status others). The observed pattern turns out to be very similar for male and female as well as for more and less attractive participants, and is robust to a large set of controls. We also report results from a control condition that was run to rule out an explanation relying on simple "similarity" effects: In this condition everything was kept identical except that randomly induced differences between subjects are not status-relevant. In line with our hypothesis, we find no behavioral differences between conditions in this control treatment.

Our findings are related to previous experimental studies, which manipulate status and examine the effect on economically relevant behaviors. Eckel and Ball (1996) and Ball and Eckel (1998), e.g., randomly assigned high or low status, informing subjects that status is based on their answers to a preceding quiz. They find that high-status individuals receive a preferential treatment in bargaining and market interactions. Ball et al. (2001) further showed that the effects on market outcomes are robust even to an evidently random implementation of status differences. Subsequent work identified effects of status on learning (Eckel and Wilson, 2007) and voluntary contributions (Kumru and Vesterlund, 2010). ${ }^{6}$

\footnotetext{
${ }^{6}$ See Heffetz and Frank (2011) for an excellent overview.
} 
The remainder of this paper is organized as follows. The next section describes the design of the experiment, section 3 reports our results and section 4 concludes.

\section{Design of Experiment}

Main treatment. We first present the choice paradigm and our treatments before discussing procedural details. ${ }^{7}$ The goal of the experiment is to randomly assign status differences, and to study whether these differences evoke moral disengagement and violence. Accordingly, our choice paradigm involves a moral decision about inflicting pain on someone else: Subjects face a binary choice, labeled option A and option B, respectively. Choosing option A implies that the subject does not receive additional money and no pain is inflicted on another participant of same gender. Option B implies that the subject is paid 7 euros, and another participant of same gender receives a painful electric shock. The instructions are specific and inform subjects that in case of choosing option B, the electric shock is administered with two electrodes attached to the other subject's forearm. A picture illustrates this setup (see Figure 1). Subjects are further informed that the shocks are medically harmless but painful. The instructions explicitly state that the decision is about whether a subject is "willing to inflict pain on another participant in return for receiving money". Note that our choice paradigm not only involves a notion of violent behavior, but also captures a widespread conception of morality, according to which harming others in an intentional and unjustified way, especially for personal gain, is viewed as immoral (Gert and Gert, 2016).

To introduce self-relevant status differences between subjects we chose the context of sexual attractiveness. Attractiveness comparisons are based on pictures participants have sent to the experimenter about two weeks prior to the experimental session. After learning about options $\mathrm{A}$ and $\mathrm{B}$ but before making their decision, subjects are reminded about having sent their picture and informed that both they themselves as well as "the other participant" have been evaluated according to their pictures. In particular, male (female) subjects are informed that a committee consisting of three attractive women (men), aged early to mid-20s, has evaluated the pictures of the subject and the other participant of same gender by answering the following questions: (i) Which of the two men (women) looks better and is overall more attractive? (ii)

\footnotetext{
${ }^{7}$ For experimental instructions see Appendix.
} 
If you had a choice: Which of the two men (women) would you like to get to know better? (iii) With which of the two could you better imagine getting intimate? Subjects learn that the committee has formed a consensual opinion on all three questions and are then informed about the resulting evaluation.

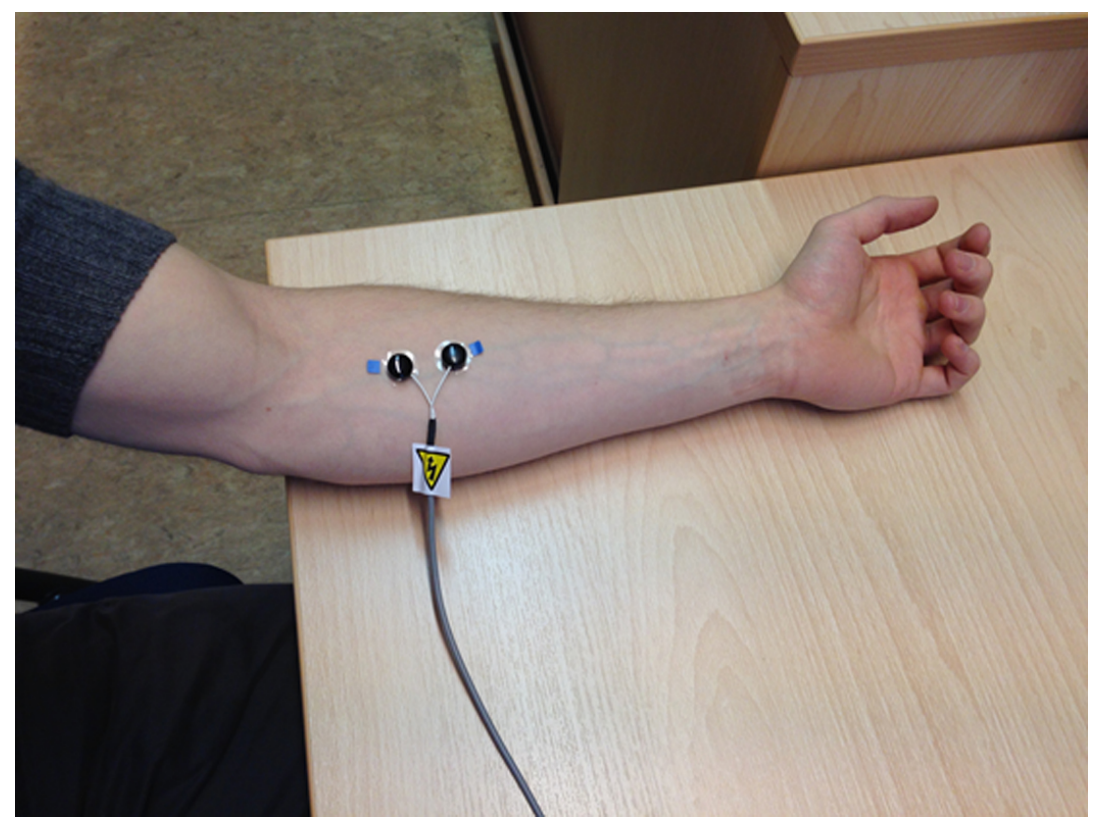

Figure 1: The picture shows how the two electrodes are attached to a person's forearm as an illustration of how electric shocks were administered. The figure was presented as part of the instructions.

Between subjects we study three conditions. In the low status condition, a participant learns that "the other participant" looks better and is more attractive, that the three committee members would rather like to get to know "the other participant", and that they could better imagine getting intimate with "the other participant" rather than with the participant. In the high status condition all three answers are in favor of the participant ("you"). In the equal status condition the answer to the three questions is always "roughly equal".

Procedures and additional measures. Figure 2 summarizes the timing of the experiment. About two weeks prior to the experimental session each participant sent his or her picture by e-mail. We explicitly asked participants to send a picture, which shows them in a "favorable way", but did not specify any reason for sending a picture. All pictures were anonymously and securely stored, printed for evaluation, and deleted immediately after the experiment. 
After all participants had sent in their picture, the six committee members, consisting of three attractive young women and three attractive young men, first (individually) assessed the attractiveness of every single subject (using the scale from Biddle and Hamermesh, 1998). Then, two groups of participants were formed. One group of subjects participated in the experiment as active "participants". The other group was selected to receive the shocks. The latter group consists of 15 female and 15 male participants. These participants did not make an active decision and only served as the "other participants". Every female "other participant" was compared to all female active participants who make a decision in the experiment, i.e., the three male committee members assessed whether the "other participant" was more, less or equally attractive than the participant in the experiment. The same was done by the three female committee members for all male participants. Based on these assessments it is possible to randomly assign the treatment status for the active participants.

Active participants were invited to the experimental lab sessions. In a given session, these participants were randomly assigned to a status condition (high, low or equal). We always made sure that the status information subjects received was correct. To ensure a corresponding truthful assignment of the "other participant", a subject was matched with someone from the pool of "other participants" who had been rated as either more, less or equally attractive. This was possible as for every subject participating in the experiment there was at least one subject among the "other participants" who was rated as more, one who was rated as less, and one who was rated as equally attractive. In other words, we implement a many-to-one matching between active participants and "other participants". Depending on the decision of the participant, the matched "other participant" received one additional shock or no additional shock. We also empirically confirm random treatment assignment in showing that treatment status is independent of objective attractiveness (see below). After the experiment, subjects received an e-mail informing them about the random assignment procedure. They were explicitly told that they could not draw any inference about their actual attractiveness from the experiment.

After active participants had been informed about their status they made their decision. Interaction was anonymous, identities of subjects were never revealed and no subject saw the picture of any other subject. At the end of an experimental session we elicited sociodemographic background characteristics together with personality related items. We also 


\begin{tabular}{|c|c|c|c|c|c|}
\hline $\begin{array}{l}\text { Two weeks prior to the } \\
\text { experimental session }\end{array}$ & $\begin{array}{l}\text { A few days before the } \\
\text { experimental session }\end{array}$ & \multirow{2}{*}{$\begin{array}{l}\text { Subjects } \\
\text { learn about } \\
\text { options A } \\
\text { and B, i.e., } \\
\text { whether to } \\
\text { inflict pain on } \\
\text { other } \\
\text { participant }\end{array}$} & \multirow{2}{*}{$\begin{array}{l}\text { Subjects learn } \\
\text { about } \\
\text { attractiveness } \\
\text { rating relative } \\
\text { to other } \\
\text { participant } \\
\text { (low, equal, or } \\
\text { high status, } \\
\text { randomly } \\
\text { assigned). }\end{array}$} & \multirow{2}{*}{$\begin{array}{l}\text { Subjects } \\
\text { make } \\
\text { decision } \\
\text { A or B }\end{array}$} & \multirow{2}{*}{$\begin{array}{l}\text { Elicitation of } \\
\text { socio- } \\
\text { demographics, } \\
\text { beliefs and } \\
\text { personality } \\
\text { related item }\end{array}$} \\
\hline $\begin{array}{l}\text { Subjects send a picture } \\
\text { showing them in a } \\
\text { "favorable" way }\end{array}$ & $\begin{array}{l}\text { Committee evaluates and } \\
\text { rates pictures (female } \\
\text { committee for male } \\
\text { subjects and vice versa) }\end{array}$ & & & & \\
\hline
\end{tabular}

Figure 2: Timeline of the experiment.

asked subjects for an assessment of their own "subjective" attractiveness on a 5-point Likert scale, using established items (Biddle and Hamermesh, 1998). This is our "subjective attractiveness" measure. Further we asked whether a subject currently has a partner, but did not inquire about sexual preferences for privacy reasons. Moreover, we asked subjects to estimate how painful the other participants actually experience receiving an electric shock. We use this estimate to control for potentially different subjective beliefs about the implications (harm) of inflicting the electric shock. This belief was elicited in an incentive compatible way. ${ }^{8}$ In addition, we elicited subject's mood on a 10-point Likert scale at the beginning of the experiment. As mentioned above, we also asked the six committee members to individually assess the attractiveness of each participant (Biddle and Hamermesh, 1998). The average of these six responses (three female and three male committee members) is our "objective attractiveness" measure. ${ }^{9}$ Wilcoxon rank-sum tests reveal no statistically significant differences in mean objective attractiveness across the three treatment conditions. Mean ratings are 2.6 in the high-status, 2.99 in the low-status, and 2.85 in the equal-status condition, respectively. This empirically confirms the random assignment of treatment condition, which is independent of objective attractiveness.

\footnotetext{
${ }^{8}$ We used a sample of 24 subjects who have previously received a series of shocks in an unrelated study and who indicated how painful they actually experienced receiving shocks on a 7-point Likert scale. In the present experiment, we asked subjects to indicate on the same 7-point scale which number is closest to the mean rating of these other subjects. A correct answer was remunerated with two euros.

${ }^{9}$ The pairwise Pearson correlation coefficient between subjective and objective attractiveness ratings is $r=0.33(p=0.003, n=81)$ for the whole sample, and $r=0.37(p=0.012, n=44)$ for female and $r=0.22$ $(p=0.181, n=37)$ for male participants, respectively.
} 
Control treatment. One may object that potential differences observed in the main treatment conditions do not necessarily reflect status concerns, but a "similarity" effect, i.e., the fact that in the equal status condition subjects are similar to their opponent while in the other two conditions they are dissimilar. From the minimal group paradigm literature it is well known that arbitrary, seemingly irrelevant and even randomly assigned group attributes have a potential to affect behavior in favor of similar others (Tajfel and Turner, 1986). ${ }^{10}$ To some extent this concern is misguided, however, simply because any difference in status necessarily implies the existence of some sort of dissimilarity, and any experimental status manipulation therefore inevitably implies a notion of non-similarity. Put differently, status is a specific form of non-similarity but not every dissimilarity is status relevant. To show that our effects are in fact driven by status differences and to rule out a simple similarity argument, we ran a control experiment with three conditions.

These conditions are identical to the main treatment, except that the committee members did not form an assessment on attractiveness, which is status relevant, but on a subject's "hair characteristics", an arguably status irrelevant feature of their physical appearance. In particular, in the control conditions three young women (men) agreed on the following three questions: (i) Which of the two men (women) has shorter hair? (ii) Which of the two men (women) has darker hair? (iii) Which of the two men (women) has curlier hair? Response categories, randomly assigned, were as in the main treatment, either "the other participant" (LowC), "you" (HighC), or "roughly equal" (EqualC). Thus, if similarity with respect to one's physical appearance is the driving force behind the observed pattern in our main treatments, we should see a similar pattern in the control treatments. In contrast, if status inequality is the main driver, we should see weaker or no differences in the control conditions relative to the main conditions.

Subjects. A total of 172 undergraduate students from the University of Bonn were recruited for the six conditions as decision makers (mean age 22.95 (4.57), 57 percent female). 81 students participated in one of the three main conditions (27 subjects in each condition) and 91 students participated in one of the three control conditions (28-32 subjects in each

\footnotetext{
${ }^{10}$ Note that the present experiment differs from the typical minimal group paradigm in important ways: First, in our experiment subjects are not members of two groups, simultaneously facing a similar and a dissimilar other. Rather, subjects are only facing one other subject who is either similar, or different. Second, differences between subjects are not induced by subjects' stated preferences, e.g., in the form of stating a preference for paintings ("Kandisky vs. Klee"), but by the judgment of a third party, the committee members.
} 
condition). Across conditions both genders were evenly distributed. In addition, 50 students were recruited as "other participants" and received electric shocks. The committee members (three women and three men, aged 20-25) were selected based on their attractiveness. For reasons of privacy and anonymity they are not students from the University of Bonn. They did not know any subject in the experiment. Informed consent for participation was obtained from all participants. For participation subjects received a show-up fee of 10 euros and an additional 7 euros if they delivered a shock to the other participant. The "other participants" received a show-up fee of 20 euros for participation, irrespective of the number of shocks they received. The electric shock paradigm was approved by the Ethics Committee of the University of Bonn (reference no. 156/13).

Moral Disengagement Hypothesis. We hypothesized that status differences affect the relative weight subjects place on the well-being of an opponent: In comparison to facing an equal status other, subjects facing opponents of either higher or lower status will identify less with their opponents and accordingly will place lower weight on their well-being. As a consequence, when facing the trade-off between acting morally (not inflicting harm on another human) and goals of self-interest (earning money) subjects matched with either high or lowstatus others will exhibit lower moral concerns, i.e., a higher propensity to act violently, in comparison to subjects matched with equal-status others. In terms of social preference models, this notion of "moral disengagement" can be thought of as a weighing parameter that is relationship-specific and accounts for the status relation between individuals.

In psychology, "moral disengagement" vis-à-vis others of either higher or lower status has been attributed to feelings of envy and contempt, which ultimately originate from social comparison processes (Fiske et al., 2002): ${ }^{11}$ In particular, when individuals compare themselves with higher-status others they may experience feelings of envy. The latter has been defined as "an unpleasant and often painful blend of feelings characterized by inferiority, hostility and resentment caused by comparison with a person or group of persons who possess something we desire" (Smith and Kim, 2007; see also Gold, 1996; Smith et al., 1999), often aiming at hurting

\footnotetext{
${ }^{11}$ Social comparison, ubiquitous in humans, serves multiple goals, such as self-evaluation and selfenhancement, see, e.g., Festinger (1954), Suls and Miller (1977), Suls et al. (2002), Wood (1989). However, favorable or unfavorable social comparisons have the potential to poison interpersonal relations (Fischer and Roseman, 2007; Fiske, 2010; Fiske et al., 2002; Galinsky et al., 2006; Russell and Fiske, 2008). Negative effects of unfavorable comparisons in terms of average neighborhood income levels and individual measures of happiness are reported in Luttmer (2005), and similarly for wages of co-workers, family or friends in Clark et al. (2009) and Card et al. (2012); on emotions and violence see also Card and Dahl (2011).
} 
and ruining the envied other. Likewise, comparing with lower-status others may trigger feelings of contempt or scorn. The latter refer to "feelings of disapproval toward others who appear unworthy of one's notice, respect, or concern" (Bell, 2013; see also Fischer and Roseman, 2007; Russell and Fiske, 2008), e.g., in the sense of feeling contempt for a weakling. Importantly, both emotions share in common a tendency of psychological withdrawal or disengagement, i.e., a reduced sympathetic identification with the object of one's envy or scorn (Klein, 1975; Takahashi et al., 2009). Note that no such effect was expected in our control condition where differences between subjects (hair quality) are not status relevant and therefore not expected to trigger feelings of envy or scorn.

\section{Results}

Figure 3 shows our main result and provides support for the moral disengagement hypothesis. In the equal status condition, 29.6 percent of subjects choose option B, thereby inflicting pain on the other participant. In the high status as well as the low status conditions, the percentage is 74.1 percent. The difference between the high and the equal status condition is statistically significant $\left(p=0.001, \chi^{2}(1)=10.68, n=54\right)$. The same holds for the comparison between the low status and the equal status conditions $\left(p=0.001, \chi^{2}(1)=10.68, n=54\right)$. Thus, compared to equal status, significantly more subjects are willing to inflict a painful electric shock to another participant, conditional on learning that they are rated higher or lower in terms of sexual attractiveness. The fact that the same fractions of subjects choose option B in the high and low status conditions is of course a coincidence. It is noteworthy, however, that the effects are not only substantial but also very similar for high and low status, suggesting that feelings of scorn and contempt can be as powerful as feelings of envy.

Table 1 provides further details and robustness checks. We report regression results for linear probability models with shocking as binary dependent variable. ${ }^{12}$ In the first column shocking is regressed on treatment dummies. The coefficients for high and low status are both positive and statistically significant at any conventional level. In columns 2 and 3 we explore whether the effect is robust to including control variables, in particular gender, age, disposable income, religiosity, whether the subject currently has a partner, his or her self-assessed (subjective)

\footnotetext{
${ }^{12}$ For ease of interpretation we report OLS estimates. Probit estimates yield the same results.
} 


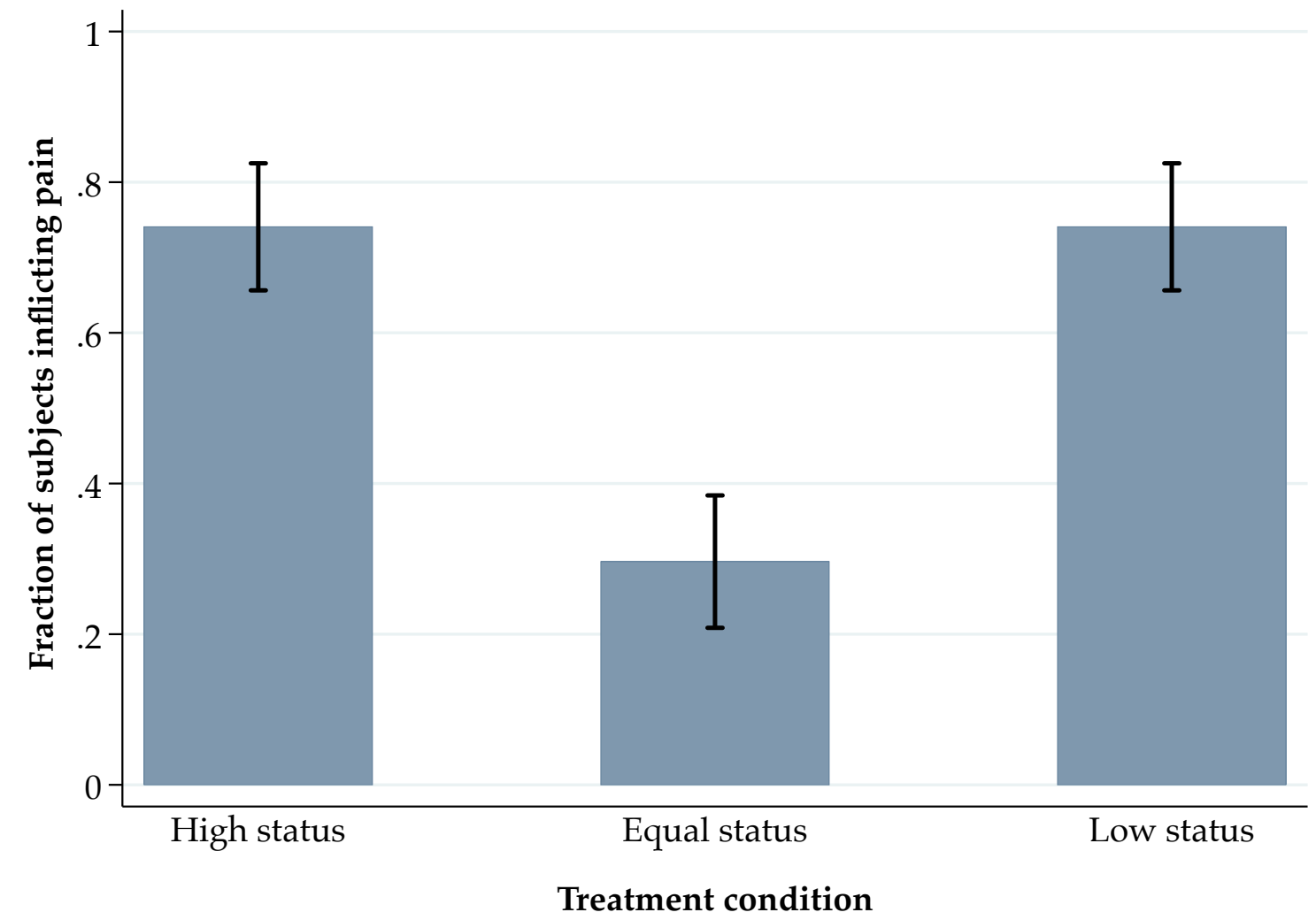

Figure 3: Fraction of subjects inflicting an electric shock in the three treatment conditions. Error bars show \pm 1 SEM.

attractiveness, an objective attractiveness assessment elicited from the six committee members, subjects' beliefs about how painful the shock actually is, and current mood measured at the beginning of the experiment. Results show that the coefficients of interest, the two treatment dummies, are essentially unaffected and remain statistically significant. We find no main effect of subjective or objective attractiveness ratings on shocking. ${ }^{13}$ Male subjects choose option B somewhat more often than female subjects (67.6 vs. 52.3 percent, $p=0.163$, $\left.\chi^{2}(1)=1.95\right)$.

Given the limited sample size, we restrict our analysis of heterogeneity in treatment effects on two factors. First, status-seeking behavior is often found to be more pronounced among men than women. For example, neurobiological research has established a strong relationship

\footnotetext{
${ }^{13}$ Instead of controlling linearly for our measures of objective and subjective attractiveness, we also ran nonparametric robustness specifications in which we included fixed effects for binned levels of theses measures. This addresses potential non-linearities in their effects on shocking. In all specifications, fixed effects remain jointly insignificant.
} 
between testosterone, the primary male sex hormone, and the search for status (Eisenegger et al., 2011). ${ }^{14}$ We therefore split the sample by gender. As shown in Panel A of Figure 4, treatment effects are essentially identical across genders in our data. ${ }^{15}$ Testing the joint hypothesis of both interaction effects of treatments (high and low) with gender being equal to zero yields a p-value of $0.8508(n=81)$. The same holds for the comparison between low status and equal status (for females $p=0.048(n=29)$, for males $p=0.013(n=25)$, Fisher's exact tests, one-sided). Second, we test whether the treatment effect varies across levels in the specific dimension in which status differences are implemented. Panel B of Figure 4 therefore shows treatment effects after splitting the sample at the median objective attractiveness rating provided by the committee. Again, the pattern is similar, suggesting that the effects are not primarily driven by either one of these groups. ${ }^{16}$ Moreover, there is no statistically significant association between beliefs about the painfulness of shocks and the decision to shock the other participant (the correlation is $r=0.0039(p=0.9725, n=81))$. This suggests that the decision to inflict an electric shock is neither driven by differential beliefs about pain, nor that these beliefs are biased by processes of motivated beliefs in the sense that subjects are trying to justify their decision in terms of envisioning low pain levels. ${ }^{17}$

As stated above, an alternative interpretation of the observed behavioral pattern is that in the equal status condition, subjects are similar to their opponent while in the other two conditions they are dissimilar. Results from our control treatment show, however, that a simple "similarity" argument is not sufficient to explain the observed behavioral pattern: While the fraction of subjects who inflict pain in the control conditions is on average similar to the main treatment (59.3 percent vs. 63.7 percent, $\left.p=0.547, \chi^{2}(1)=0.3632, n=172\right)$, there is no systematic difference between the three control conditions. In fact, the fraction of shocking

\footnotetext{
${ }^{14}$ Achieving and maintaining high status is the definition of so-called "dominance behavior". A large body of evidence attests to the role of testosterone in promoting dominant and power-seeking behaviors in both humans (Mazur and Booth, 1998; Dabbs et al., 1990) and animals (Mazur, 2005), which is viewed as an important source of differences in status-seeking behavior between genders.

${ }^{15}$ For both genders the differences between the high and the equal status condition is statistically significant (for females $p=0.033(n=30)$, for males $p=0.018(n=24)$, Fisher's exact tests, one-sided).

${ }^{16}$ Attractiveness does not significantly affect treatment effects: We regress the decision to shock the other participant on the two treatment dummies (high and low), objective attractiveness, and the interactions of treatments and attractiveness. Testing the joint hypothesis that both interaction terms are equal to zero can be rejected at $p=0.5768$. Using the same specification for subjective attractiveness, the respective p-value is 0.4718 .

${ }^{17} \mathrm{~A}$ caveat concerning this statement is of course that the estimate of painfulness is elicited at the end of the experiment, i.e., this measure is potentially affected by treatment condition and is endogenous to the shocking choice. On motivated beliefs and reasoning, see, e.g., Exley (2016) or Gino et al. (2017).
} 


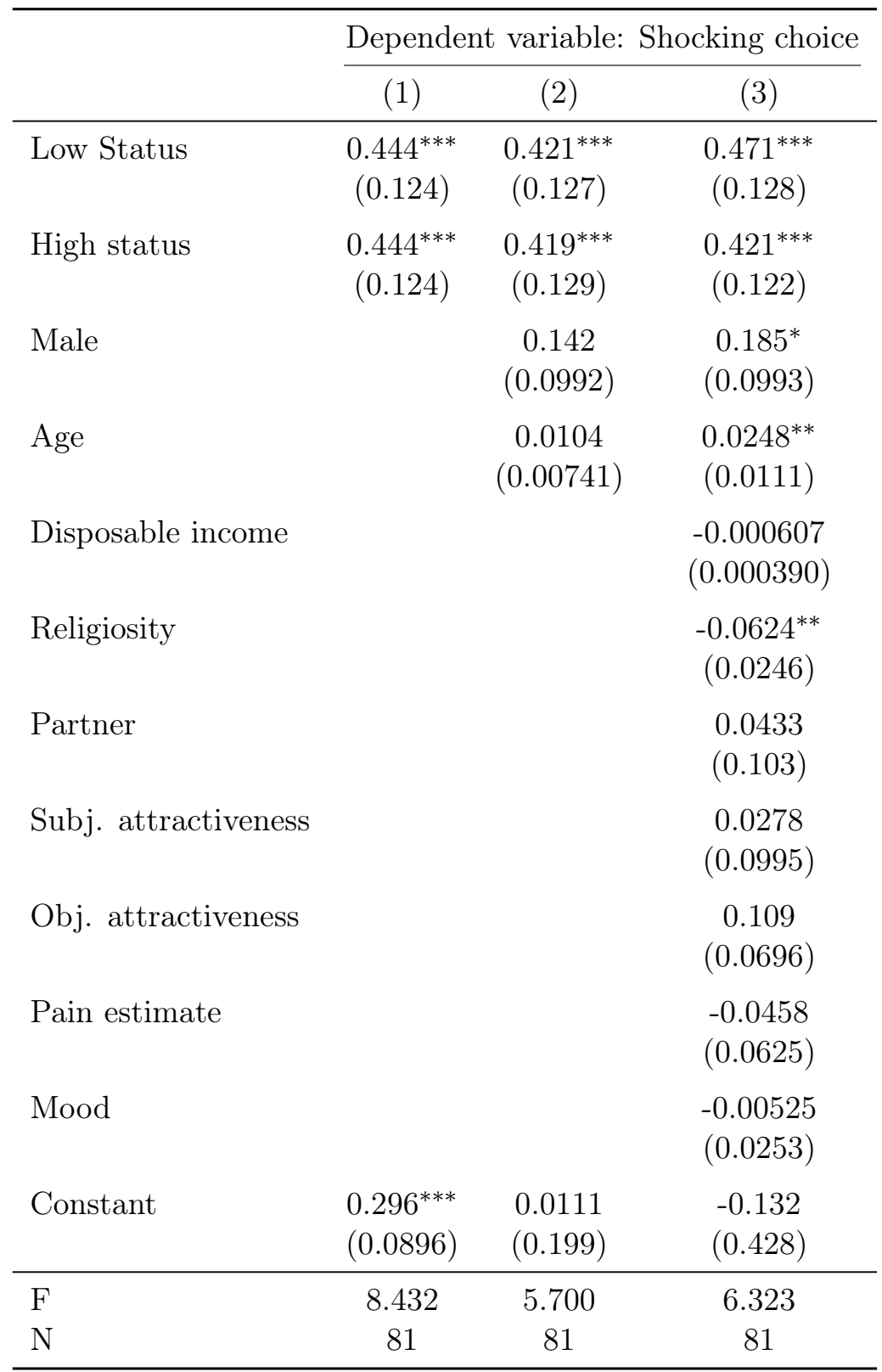

Table 1: OLS regression coefficient estimates with inflicting pain as binary dependent variable and standard errors in parentheses (1 if the subject inflicted pain, and zero otherwise). Low status and High Status are treatment dummies, with Equal Status as omitted category. Disposable income is monthly disposable income (in Euro). Religiosity measures subjects' self-assessment concerning how religious they are (Likert scale from 1 (not at all) to 7 (very much)), Partner indicates whether a subject currently has a partner, Subjective attractiveness is self-assessed attractiveness, Objective attractiveness refers to the mean rating of the six committee members, Pain estimate is a subject's (incentivized) estimate of how painful the electric shock is, Mood measures current mood at the beginning of the experiment (Likert scale from 1 (very bad) to 10 (very good)). Robust standard errors in parantheses. ${ }^{*} \mathrm{p}<$ $0.10,{ }^{* *} \mathrm{p}<0.05,{ }^{* * *} \mathrm{p}<0.01$. 


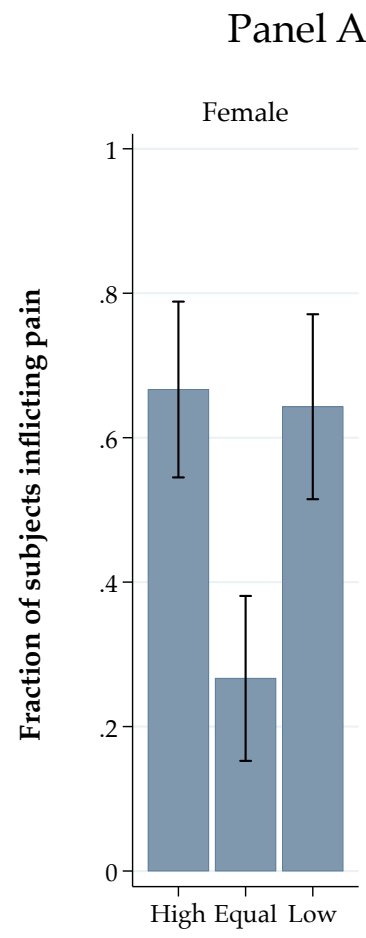

Panel A: Gender
Male

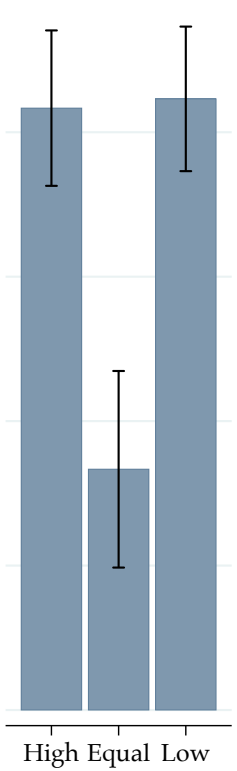

Panel B: Objective attractiveness

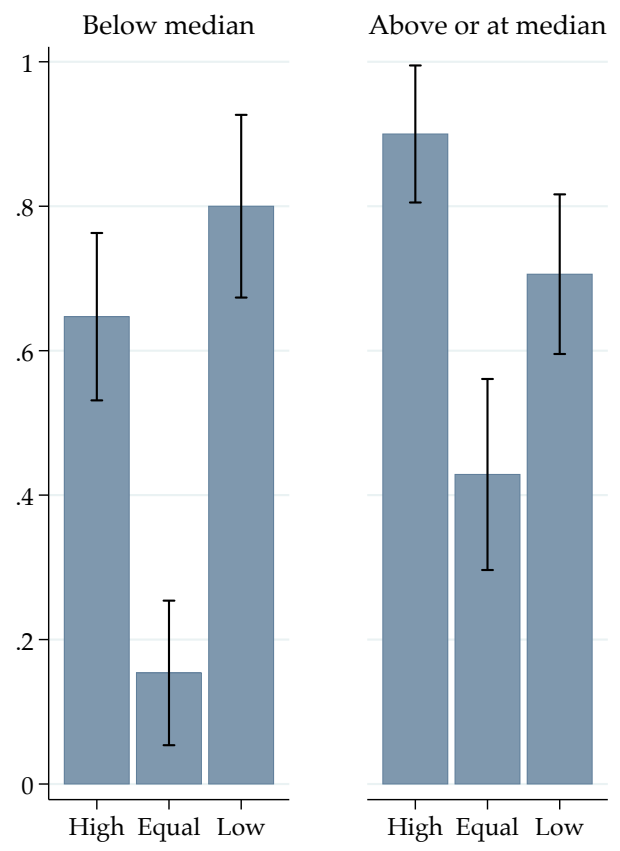

Treatment condition

Figure 4: The figure displays the fraction of subjects inflicting electric shocks in the three treatment conditions, split by gender (Panel A) or split by having received an attractiveness score below vs. above or at the median. Error bars show \pm 1 SEM.

is actually highest in the equal condition (EqualC). Shocking rates are 57.1 percent in the HighC condition $(n=28), 65.6$ percent in the LowC condition $(n=32)$, and 67.7 percent in the EqualC condition $(n=31)$, respectively. None of the treatment differences is statistically significant (EqualC vs. LowC: $p=0.859$ ( $n=63$ ); EqualC vs. HighC: $p=0.401(n=59)$; LowC vs. HighC: $p=0.500(n=60)$, respectively; $\chi^{2}$ tests $)$. Thus, we find no indication of a significant difference when comparing similar to non-similar subjects in the status neutral control condition, suggesting that the main finding reflects status concerns, rather than a simple similarity notion. In the Appendix, we report difference-in-difference estimates for the full sample including treatment and control conditions (see Table 2). The regressions confirm significant treatment effects for high and low status in the main treatment conditions in comparison to same status, relative to the (insignificant) treatment effects in the control 
condition. In each column, the difference-in-difference estimates of low and high status are statistically indistinguishable $(p>0.52)$.

\section{Concluding remarks}

This paper contributes to our understanding of the social cost of inequality in providing causal evidence that status inequality evokes moral disengagement and violent behavior. In particular, our results suggest that visible perceptions of status inequality can have detrimental effects on the quality of social relationships and hence societal cohesion. While the experimental paradigm implements status differences in the realm of sexual competition - a context that allows us to randomly assign status differences in a self-relevant domain in the lab -, the potential of status differences to trigger violence is of course not confined to this type of context but applies more generally to status-relevant contexts, e.g., in the economic and social domain. Social differences which are relevant to status hierarchy are, among others, occupation, unemployment, education, race, gender, age or ethnicity (Ridgeway, 2006).

Previous work on status effects using field data has studied horizontal violence, e.g., violence among the group of disadvantaged, or it has been unclear as to whether the target of violence is of higher, lower or similar status. In the present paper we cleanly delineate the status relation and show that status differences trigger violence both vis-à-vis others of higher and lower status. We do not study, however, whether the experience of high or low status triggers violence vis-à-vis others of the same status, i.e., among participants who receive the same positive (negative) signal from a comparison with a third person. An interesting follow-up study would induce the same high or low status among two participants and check potential consequences for immoral behavior. This is different to our equal status condition where participants are not assigned a high or low status. In this context, note that the present paper investigates the role of status inequality, not of status per se. ${ }^{18}$

Our findings also contribute to research on the determinants of morality and point out potential shortcomings of models of social preferences. In particular, they add to the growing body of evidence suggesting that moral behavior is not solely determined by universal principles

\footnotetext{
${ }^{18}$ Piff et al. (2010), e.g., argue that members of the upper-class act more selfishly than lower-class individuals. In contrast, Becker et al. (2012) and Bauer et al. (2014) report evidence on higher levels of prosociality among children (and parents) with a high socio-economic status relative to low socio-economic status individuals.
} 
(such as utilitarianism or deontological reasoning), but is instead malleable, varying by social, institutional or emotional context (Kesebir and Haidt, 2010). The results of this study also inform models of social preferences in showing that above and beyond what is typically captured in these models, status differences affect how individuals weigh the well-being of others. In terms of social preference models, this implies that the willingness to exert a positive or negative externality on another individual goes beyond notions of inequity aversion (Fehr and Schmidt, 1999), reciprocating kindness (Rabin, 1993; Falk and Fischbacher, 2006) or image concerns (Benabou and Tirole, 2006). Rather, our results show that the trade-off between motives of self interest (receiving money) and exerting a negative externality is strongly affected by the nature of the social relationship between individuals (Loewenstein et al., 1989). Put differently, the relative weight we place on the well-being of an opponent crucially hinges on status considerations, above and beyond distributional, image or reciprocity concerns. 


\section{References}

Alesina, A., Glaeser, E., and B. Sacerdote (2001). "Why doesn't the US have a Europeanstyle welfare system?". NBER Working Paper, No. 8524.

Anderson, D. A. (1999). "The aggregate burden of crime". The Journal of Law and Economics, 42(2): 611-642.

Ball, S. B., and C. C. Eckel (1998). "The economic value of status". The Journal of SocioEconomics, 27(4): 495-514.

Ball, S. B., Eckel, C. C., Grossman, P. J., and Zame, W. (2001). "Status in markets". The Quarterly Journal of Economics, 116(1): 161-188.

Bandura, A. (1999). "Moral disengagement in the perpetration of inhumanities". Personality and Social Psychology Review, 3(3): 193-209.

Bassuk, E. L., Weinreb, L. F., Buckner, J. C., Browne, A., Salomon, A., and Bassuk, S. S. (1996). "The characteristics and needs of sheltered homeless and low-income housed mothers". Journal of the American Medical Association, 276: 640-646.

Bauer, M., Chytilovà, J., and Pertold-Gebicka, B. (2014). "Parental background and otherregarding preferences in children". Experimental Economics, 17(1): 24-46.

Becker, A., Deckers, T., Dohmen, T., Falk, A., and Kosse, F. (2012). "The Relationship between Economic Preferences and Psychological Personality Measures". Annual Review of Economics, 4: 453-478.

Bénabou, R., and J. Tirole (2006). "Incentives and prosocial behavior". The American Economic Review, 96(5): 1652-1678.

Bell, M. (2013). Hard Feelings: The Moral Psychology of Contempt. New York: Oxford University Press.

Biddle, J. E., and D. S. Hamermesh (1998). "Beauty, Productivity, and Discrimination: Lawyers' Looks and Lucre". Journal of Labor Economics, 16(1): 172-201.

Blau, J. R., and P. M. Blau (1982). "The cost of inequality: Metropolitan structure and violent crime." American Sociological Review, 47(1): 114-129.

Bowles, S., and Y. Park (2005). "Emulation, inequality, and work hours: Was Thorsten Veblen right?". The Economic Journal, 115(507): 397-412.

Browne, A., Salomon, A., and Bassuk, S. S. (1999). "The impact of recent partner violence on poor women?s capacity to maintain work". Violence Against Women, 5: 393-426.

Buka, S. L., Stichick, T. L., Birdthistle, I., and Felton, S. M. (2001). "Youth exposure to violence: Prevalence, risks, and consequences". American Journal of Orthopsychiatry, 71: $298-310$.

Card, D., Dustmann, C., and Preston, I. (2012). "Immigration, wages, and compositional amenities". Journal of the European Economic Association, 10(1): 78-119. 
Card, D., and G. B. Dahl (2011). "Family violence and football: The effect of unexpected emotional cues on violent behavior". The Quarterly Journal of Economics, 126(1): 103143.

Card, D., Heining, J., and P. Kline (2013). "Workplace heterogeneity and the rise of West German wage inequality" The Quarterly Journal of Economics, 128(3): 967-1015.

Clark, A. E., Kristensen, N., and Westergard-Nielsen, N. (2009). "Job Satisfaction and Coworker Wages: Status or Signal?". The Economic Journal, 119(536): 430-447.

Dabbs, J. M., de La Rue, D., and P. M. Williams (1990). "Testosterone and occupational choice: actors, ministers, and other men". Journal of Personality and Social Psychology, 59(6): 1261.

Daly, M., Wilson, M., and S. Vasdev (2001). "Income inequality and homicide rates in Canada and the United States". Canadian Journal of Criminology, 43: 219-236.

Dustmann, C., Ludsteck, J. and U. Schonberg (2009). "Revisiting the German wage structure". The Quarterly Journal of Economics, 124(2): 843-881.

Eckel, C. C., and S. B. Ball (1996). "Buying status: Experimental evidence on status in negotiation". Psychology and Marketing, 13(4): pp.381-405.

Eckel, C. C., and R. K. Wilson (2007). "Social learning in coordination games: does status matter?". Experimental Economics, 10(3), 317-329.

Eisenegger, C., Haushofer, J., and E. Fehr (2011). "The role of testosterone in social interaction". Trends in Cognitive Sciences, 15(6): 263-271.

Exley, C. L. (2016). "Excusing Selfishness in Charitable Giving: The Role of Risk". Review of Economic Studies, 83(2): 587-628.

Fajnzylber, P., Lederman, D., and N. Loayza (2002). "What causes violent crime?". European Economic Review, 46(7): 1323-1357.

Falk, A., and U. Fischbacher (2006). "A theory of reciprocity". Games and Economic Behavior, 54(2): 293-315.

Falk, A., Kuhn, A., and J. Zweimüller (2011). "Unemployment and Right-wing Extremist Crime". Scandinavian Journal of Economics, 113(2): 260-285.

Fehr, E., and K. M. Schmidt (1999). "A theory of fairness, competition, and cooperation". The Quarterly Journal of Economics, 114(3): 817-868.

Festinger, L. (1954). "A Theory of Social Comparison Processes". Human Relations, 7(2): $117-140$.

Fischer, A. H., and I. J. Roseman (2007). "Beat them or ban them: the characteristics and social functions of anger and contempt". Journal of Personality and Social Psychology, 93(1): 103-115.

Fiske, S. T. (2010). "Envy Up, Scorn Down: How Comparison Divides Us". American Psychologist, 65(8): 698-706. 
Fiske, S. T., Cuddy, A. J. C., Glick, P., and J. Xu (2002). "A model of (often mixed) stereotype content: competence and warmth respectively follow from perceived status and competition". Journal of Personality and Social Psychology, 82(6): 878-902.

Foot, P. (1978). "The problem of abortion and the doctrine of the double effect", In Foot, P. (Ed.), Virtues and Vices and Other Essays in Moral Philosophy (pp. 19-32). Berkeley: University of California Press.

Galinsky, A. D., Magee, J. C., Inesi, M. E., and D. H. Gruenfeld (2006). "Power and perspectives not taken". Psychological Science, 17(12): 1068-1074.

Gert, B. and J. Gert (2016) "The Definition of Morality". The Stanford Encyclopedia of Philosophy (Spring 2016 Edition), Edward N. Zalta (ed.).

Gino, F., Norton, M. I., and Weber, R. A. (2016). "Motivated Bayesians: Feeling moral while acting egoistically". The Journal of Economic Perspectives, 30(3), 189-212.

Glaeser, E. L. (2005). "The political economy of hatred". The Quarterly Journal of Economics, 120(1): 45-86.

Glick, P. (2002). 'Sacrificial lambs dressed in wolves' clothing: Envious prejudice, ideology, and the scapegoating of Jews". In Newman, L., and R. Erber (Eds.) Understanding Genocide: The Social Psychology of the Holocaust (pp. 113-142). New York: Oxford University Press.

Glover, J. (2012). "Humanity". Yale University Press.

Gold, B. T. (1996). "Enviousness and its relationship to maladjustment and psychopathology". Personality and Individual Differences, 21(3): 311-321.

Heffetz, O., and R. H. Frank (2011). "Preferences for Status: Evidence and Economic Implications". In Benhabib, J., Bisin, J., and M. O. Jackson (Eds.), Handbook of Social Economics (pp. 69-91). North-Holland.

Hsieh, C.-C., and M. D. Pugh (1993). "Poverty, income inequality, and violent crime: a metaanalysis of recent aggregate data studies". Criminal Justice Review, 18(2): 182-202.

Kalick, S. M. (1988). "Physical attractiveness as a status cue". Journal of Experimental Social Psychology, 24(6): 469-489.

Kelly, M. (2000). "Inequality and Crime". Review of Economics and Statistics, 82: 530-539.

Kesebir, S., and J. Haidt (2010). "Morality". In Fiske, S., Gilbert, D., and G. Lindzey (Eds.), Handbook of Social Psychology (pp. 797-832). Hoboken, New Jersey: Wiley.

Klein, M. (1975). "Envy and Gratitude and Other Works, 1946-1963". London: Hogarth Press.

Kumru, C. S., and Vesterlund, L. (2010). "The effect of status on charitable giving". Journal of Public Economic Theory, 12(4), 709-735. 
Lipsey, M. W., and Derzon, J. H. (1998). "Predictors of violent and serious delinquency in adolescence and early adulthood: A synthesis of longitudinal research", In R. Loeber and D. P. Farrington (Eds.), Serious and violent juvenile offenders: Risk factors and successful interventions (pp. 86-105). Thousand Oaks, CA: Sage Publications.

Loewenstein, G. F., Thompson, L., and Bazerman, M. H. (1989). "Social utility and decision making in interpersonal contexts". Journal of Personality and Social Psychology, 57: 426-441.

Luttmer, E. F. P. (2005). "Neighbors as Negatives: Relative Earnings and Well-Being". Quarterly Journal of Economics, 120(3): 963-1002.

Maner, J. K., Kenrick, D. T., Becker, D. V., Robertson, T. E., Hofer, B., Neuberg, S. L., Delton, A. W., Butner, J., and M. Schaller (2005). "Functional projection: how fundamental social motives can bias interpersonal perception". Journal of Personality and Social Psychology, 88(1): 63-78.

Mazur, A. (2005). "Biosociology of dominance and deference". Rowman and Littlefield Publishers.

Mazur, A., and A. Booth (1998). "Testosterone and dominance in men". Behavioral and brain sciences, 21(3): 353-363.

Milgram S. (1974). "Obedience to Authority: An Experimental View". New York: Harper and Row.

Petrinovich, L., and O'Neill, P. (1996). "Influence of wording and framing effects on moral intuitions". Ethology and Sociobiology, 17(3): 145-171.

Piff, P. K., Kraus, M. W., Coté, S., Cheng, B. H., and Keltner, D. (2010)". Having less, giving more: the influence of social class on prosocial behavior". Journal of personality and social psychology, 99(5): 771.

Rabin, M. (1993). "Incorporating fairness into game theory and economics". The American Economic Review, 83(5): 1281-1302.

Ridgeway, C. L. (2006). "Status construction theory". In Burke, P. J. (Ed.), Contemporary Social Psychological Theories (pp. 301-323). Stanford: Stanford University Press.

Resnick, M. D., Ireland, M., and Borowsky, I. (2004). "Youth violence perpetration: What protects? What predicts? Findings from the National Longitudinal Study of Adolescent Health". Journal of Adolescent Health, 35: 424-434.

Ridgeway, C. L., Boyle, E. H., Kuipers, K. J., and D. T. Robinson (1998). "How Do Status Beliefs Develop? The Role of Resources and Interactional Experience". American Sociological Review, 63: 331-350.

Roberts, J. A. (2011). "Shiny Objects: Why we spend money we don't have in search of happiness we can't buy". Harper Collins.

Russell, A., and S. Fiske (2008). "It's all relative: Competition and status drive interpersonal perception". European Journal of Social Psychology, 38(7): 1193-1201. 
Saez, E., and S. Stantcheva (2016). "Generalized social marginal welfare weights for optimal tax theory". The American Economic Review, 106(1): 24-45.

Sapolsky, R. M. (2004). "Social Status and Health in Humans and Other Animals". Annual Review of Anthropology, 33(1): 393-418.

Smith, R. H., and Kim, S. H. (2007). "Comprehending envy". Psychological Bulletin, 133(1): 46-64.

Smith, R. H., Parrott, W. G., Diener, E. F., Hoyle, R. H., and S. H. Kim (1999). "Dispositional Envy". Personality and Social Psychology Bulletin, 25(8): 1007-1020.

Soares, R. R. (2006). "The welfare cost of violence across countries". Journal of Health Economics, 25(5): 821-846.

Song, J., Price, D.J., Guvenen, F., Bloom, N. and T. Von Wachter (2015). "Firming up inequality". NBER Working Paper, No. 21199.

Suls, J., Martin, R., and L. Wheeler (2002). "Social Comparison: Why, With Whom, and With What Effect?". Current Directions in Psychological Science, 11(5): 159-163.

Suls, J., and R. Miller (1977). Social Comparison Processes: Theoretical and Empirical Perspectives. Washington DC: Hemisphere Publishing Corporation.

Tajfel, H., and J. Turner (1986). "The social identity theory of intergroup behavior". In Austin, W., and S. Worchel (Eds.) Psychology of Intergroup Relations (pp. 7-24). Chicago: Nelson-Hall Publishers.

Thaler, R. (1978). "A note on the value of crime control: evidence form the property market". Journal of Urban Economics, 5: 137-145.

Tirole, J., Falk, A., Bénabou, R. (2017) "Narratives, Imperatives, and Moral Reasoning". Mimeo.

Takahashi, H., Kato, M., Matsuura, M., Mobbs, D., Suhara, T., and Okubo, Y. (2009). "When your gain is my pain and your pain is my gain: neural correlates of envy and schadenfreude". Science, 323(5916): 937-939.

Wilkinson, R. (2004). "Why is violence more common where inequality is greater?" Annals of the New York Academy of Sciences, 1036(1): 1-12.

Wilkinson, R. and K. Pickett (2009). "The spirit level: Why more equal societies almost always do better". London: Allen Lane.

Wood, J. (1989). "Theory and research concerning social comparisons of personal attributes". Psychological Bulletin, 106(2): 231-248.

World Health Organization. (2002). "World report on violence and health". Geneva: World Health Organization.

Zimbardo, P. G. (2007). "Lucifer Effect". Blackwell Publishing Ltd. 
Zink, C. F., Tong, Y., Cheng, Q., Bassett, D. S., Stein, J. L., and Meyer-Lindenberg, A. (2008). "Know Your Place: Neural Processing of Social Hierarchy in Humans". Neuron, 58(2): $273-283$. 


\section{Appendix}

\section{A Difference-in-difference Analysis}

Table 2 shows difference-in-difference estimates for the full sample including treatment and control conditions. The regressions confirm significant treatment effects for high and low status in the main treatment condition in comparison to same status, relative to the (insignificant) treatment effects in the control condition. In each column, the difference-in-difference estimates of low and high status are statistically indistinguishable $(p>0.52)$. 


\begin{tabular}{|c|c|c|c|}
\hline & \multicolumn{3}{|c|}{ Dependent variable: Shocking choice } \\
\hline & (1) & $(2)$ & $(3)$ \\
\hline Feedback: low & $\begin{array}{c}0.444^{* * *} \\
(0.124)\end{array}$ & $\begin{array}{c}0.416^{* * *} \\
(0.127)\end{array}$ & $\begin{array}{c}0.444^{* * *} \\
(0.123)\end{array}$ \\
\hline Feedback: high & $\begin{array}{c}0.444^{* * *} \\
(0.124)\end{array}$ & $\begin{array}{c}0.418^{* * *} \\
(0.127)\end{array}$ & $\begin{array}{c}0.419^{* * *} \\
(0.126)\end{array}$ \\
\hline Control condition & $\begin{array}{c}0.381^{* * *} \\
(0.124)\end{array}$ & $\begin{array}{c}0.369^{* * *} \\
(0.123)\end{array}$ & $\begin{array}{c}0.382^{* * *} \\
(0.127)\end{array}$ \\
\hline Control $*$ Feedback: low & $\begin{array}{c}-0.466^{* * *} \\
(0.173)\end{array}$ & $\begin{array}{c}-0.421^{* *} \\
(0.167)\end{array}$ & $\begin{array}{c}-0.433^{* * *} \\
(0.165)\end{array}$ \\
\hline Control * Feedback: high & $\begin{array}{c}-0.550^{* * *} \\
(0.178)\end{array}$ & $\begin{array}{c}-0.527^{* * *} \\
(0.178)\end{array}$ & $\begin{array}{c}-0.522^{* * *} \\
(0.183)\end{array}$ \\
\hline Male & & $\begin{array}{l}0.271^{* * *} \\
(0.0667)\end{array}$ & $\begin{array}{l}0.270^{* * *} \\
(0.0673)\end{array}$ \\
\hline Age & & $\begin{array}{c}0.0107^{*} \\
(0.00571)\end{array}$ & $\begin{array}{c}0.0116^{*} \\
(0.00649)\end{array}$ \\
\hline Disposable income & & & $\begin{array}{l}-0.000169 \\
(0.000225)\end{array}$ \\
\hline Religiosity & & & $\begin{array}{l}-0.0337^{*} \\
(0.0181)\end{array}$ \\
\hline Partner & & & $\begin{array}{c}0.0119 \\
(0.0712)\end{array}$ \\
\hline Pain estimate & & & $\begin{array}{c}0.0126 \\
(0.0347)\end{array}$ \\
\hline Constant & $\begin{array}{c}0.296^{* * *} \\
(0.0895)\end{array}$ & $\begin{array}{c}-0.0532 \\
(0.160)\end{array}$ & $\begin{array}{c}0.00701 \\
(0.236)\end{array}$ \\
\hline $\mathrm{F}$ & 3.589 & 5.981 & 4.823 \\
\hline $\mathrm{N}$ & 172 & 172 & 172 \\
\hline
\end{tabular}

Table 2: OLS difference-in-differences analyses on full sample. The dependent variable has value 1 if the subject inflicted pain, and 0 otherwise. The feedback coefficients indicate the effect of the (randomized) comparison with another participant. Feedback: low means lower status in the treatment condition, or longer, lighter, and less curly hair in the control condition (vice versa for high feedback). The omitted category is neutral feedback, i.e. the other participant was of same status (treatment) or had similar hair (control). Control condition is a treatment dummy, with the treatment condition as omitted category. The differencein-differences estimators are reported as coefficients Contol ${ }^{*}$ Feedback: low/high, i.e., the interaction effects of treatment condition with randomized feedback. Disposable income is monthly disposable income (in Euro). Religiosity measures subjects' self-assessment concerning how religious they are (Likert scale from 1 (not at all) to 7 (very much)), Partner indicates whether a subject currently has a partner, Pain estimate is a subject's (incentivized) estimate of how painful the electric shock is. Robust standard errors in parantheses. ${ }^{*} \mathrm{p}<0.10,{ }^{* *} \mathrm{p}$ $<0.05,{ }^{* * *} \mathrm{p}<0.01$. 


\section{B Electric Shock Paradigm}

Electric shocks were administered using a standard electronic device frequently used in pain stimulation studies in medicine. These shocks are medically harmless but painful. The electric stimulus was administered with devices (SHK 1) manufactured by the company Psychlab. The devices are specifically tailored for scientific purposes. To administer the shock two electrodes were attached to the subject's forearm (see Fig. 1). The electrodes delivered focused and centered electric shocks. After the calibration phase, subjects received a series of shocks depending on the other subjects' decisions. Note that albeit using electric shocks, our paradigm differs from the famous Milgram experiment in several important ways (Milgram, 1974). First, our research interest is different. We study status differences between subjects rather than effects of authority or obedience. Second, our paradigm does not involve "dangerous" electric shocks. Subjects are told that shocks are painful, but not hazardous (which is the case). Third, our experiment does not involve deception. Shocks were actually administered. Finally, the experimenter remained passive and no pressure of any sort was exerted. Subjects were seated in cubicles with curtains, taking their decision anonymously on a computer; they were absolutely free to choose option A in case they wanted to avoid inflicting harm on another subject.

\section{Instructions}

In the following we provide a translation of the German instruction for the main treatment (low status condition). The control treatment was identical, except for differences explained in the main text ("hair characteristics"). We present instructions for male participants. Instructions for female participants are identical but with opposite gender roles.

Thank you very much for your participation. For your participation you will receive 10 euros. At the end of the experiment you will receive your money in cash.

Please note: Throughout the whole experiment no communication between participants is allowed. On the computer please only use the functions intended to be used. If you have questions please raise your hand. Your question will then be answered at your cubicle! 
Please note: All statements made in these instructions are true. This holds for all experiments carried out by the Bonn Economics Laboratory, and also for this experiment. In particular, all actions to be taken will be implemented exactly in the way they are described.

Depending on your decisions you can earn additional money. In addition your decisions have consequences on another participant in another experiment.

Please insert your ID number.

On a scale from 0 to 10 , how is your current mood?

Please provide your answer with help of the scale, where 0 means "very bad" and 10 means "very good".

\section{Your decision}

In the following you have the decision between Option A and Option B. If you choose Option A you will not receive additional money. If you choose Option B you will receive an additional 7 euros. Your decision has an additional consequence. If you choose Option B, another participant will receive a painful electric shock. To administer the shock two electrodes will be attached to the participant's wrist (see figure). The electric impulses are completely unproblematic from a health perspective, but very painful. Your decision in this experiment is thus whether you are willing to inflict pain on another participant in return for receiving money. You will receive further information about the other participant below.

Figure (Fig. 1)

As already pointed out you will decide between two options.

After you have decided for an option, this option will be implemented. If you have chosen Option A, you will receive no additional money and the other participant will not receive an electric shock. If you have chosen Option B, you will receive an additional $\mathbf{7}$ euros at the end of the experiment, and the other participant will receive a painful electric shock.

Please note: The other participant takes part in another experiment at a different point in time. The other participant will be informed that he may receive a painful electric shock, and will give his written consent for participation in the experiment, according to the guidelines 
of the Ethics committee. The other participant will receive money for participating in this experiment, irrespective of whether he receives an electric shock or not.

Anonymity: You will at no point get to know the identity of the other participant, and your identity will also remain completely anonymous.

Summary According to Option A you receive no additional money and the other participant receives no painful electric shock. According to Option B you receive an additional amount of money and the other participant receives a painful electric shock. The decision is yours. You will take your decision on a decision screen, which will be presented to you below.

Click on "continue" if you have read the instructions.

\section{Information about the other participant}

As you probably recall, you have sent us a picture of yourself some time before the experiment. The other participant is also male and has also sent us a picture of himself. Both pictures have been compared to each other.

To this end both pictures were evaluated by three attractive young women aged beginning to mid 20. The three women were asked, whom of the two, you or the other participant, they find more attractive. In particular, the following three questions were answered by the three women:

You see the pictures of two men. Please answer the following questions:

1. Which of the two men looks better and is overall more attractive?

2. If you had a choice: Which of the two men would you like to get to know better?

3. With which of the two could you better imagine getting intimate?

The women have jointly inspected the pictures, have discussed their answers to the three questions, and have formed a unanimous evaluation. On the next screen you will receive their joint answers with respect to these questions.

The answer is either "You", if you have been evaluated to be more attractive, "the other

participant", if the other participant has been evaluated to be more attractive, or "both roughly equal", if both have been evaluated roughly equal. 
On the next screen you will learn the evaluation of the women.

Evaluation of the women with respect to your (ID) attractiveness, in comparison to the other participant.

1. Which of the two men looks better and is overall more attractive?

\section{Answer: The other participant}

2. If you had a choice: Which of the two men would you like to get to know better?

\section{Answer: The other participant}

3. With which of the two could you better imagine getting intimate?

\section{Answer: The other participant}

On the next screen you can make your decision.

(Note that this is an example of the low status condition, feedback was "You" or "both roughly equal" in the high and equal conditions, respectively.)

\section{Please decide now:}

\section{I choose:}

\section{Option A}

\section{Confirm}

In the following subjects answered several survey questions. 